\title{
Technology, tradition unite in India's drug discovery scheme
}

India has embarked on a fast-track program to discover new drugs by building on traditional medicines and screening the country's diverse plant and microbial resources. The five-year project has already uncovered more than 40 leads, and two potential blockbuster drugs are expected to enter human trials within a year.

The unique project was prompted by the realization that after January 2005-when new intellectual property regulations come into force-Indian companies can no longer copy drugs, but must develop them on their own. Few Indian companies have the money or the resources to compete with multinational drug firms, however.

"The only way out is to use our traditional medical knowledge and biodiversity as a springboard," says Raghunath Anant Mashelkar, director general of the Council of Scientific and Industrial Research (CSIR), and the project's chief executive. "By fusing ancient wisdom and modern science, India can create world-class products, and that is what this program is all about."

After a two-year pilot phase, the full-fledged Drug Discovery Programme (DDP) began in 2000. Using both conventional and modern tools, researchers subject plant and microbial extracts and traditional medicines already on the market to an elaborate screening process.
The project now involves 900 researchers from 20 CSIR laboratories, 12 universities and several research institutions. Each year, the researchers screen extracts of 1,000 plants, 1,500 microbial strains and 25 traditional drugs, but the capacity is to double in 2005, officials say.

The CSIR spent nearly $\$ 10$ million on equipment, in vitro and animal testing facilities and modeling workstations. In the next five years, the project is expected to cost another $\$ 30$ million.

"In terms of its size, diversity and access to talent and resources, [the] DDP is not only the world's largest project of its kind but [it is] also unique," says Kondapuram Vijaya Raghavan, director of the Hyderabad-based Indian Institute of Chemical Technology, one of the participating laboratories.

Researchers are screening all products for each of 20 diseases, regardless of previously reported effects. This approach, Raghavan says, "has helped to unravel the unknown strengths of traditional drugs in terms of their multiple activities."

In the last five years, the DDP has screened 78,000 samples and obtained 150 in vitro and in vivo 'actives'. Out of those, 44 have been identified as potential Investigational New Drugs. They include new herbal formulations with antigastric activity, a new combination of

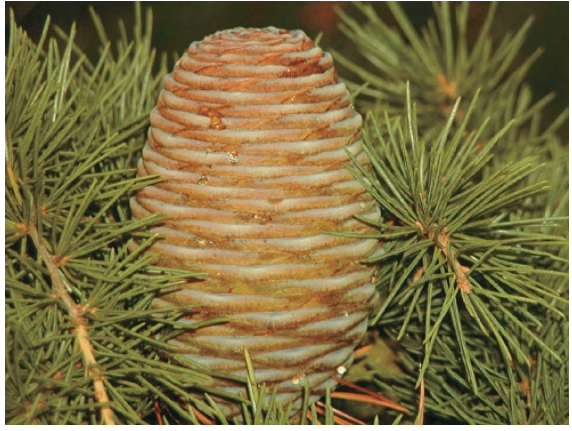

Indian researchers are testing Cedrus deodara, native to the Himalayas, against 20 diseases.

chemical entities with proven anticancer activity, an herbal preparation with memoryenhancing abilities and a number of singlemolecule compounds. The project saves time and money by focusing on naturally available molecules instead of synthesizing them from scratch, Raghavan says.

Although the project is commercial in intent, there is some need for basic research, says Raghavan. Because herbal drugs are complex mixtures, "the synergy effects in herbal drugs provide one of the most outstanding challenges in designing them," he says. "This calls for basic research to understand this phenomenon at cellular or molecular levels."

K S Jayaraman, New Delhi

\section{Japan launches controversial Biobank project}

Japan is pushing ahead with a new five-year, $\$ 180$ million project to build a bio-repository of blood and tissue samples from 300,000 citizens suffering from cancers, diabetes, rheumatoid arthritis and other common diseases. Led by high-throughput genotyping pioneer Yusuke Nakamura at the University of Tokyo's Institute for Medical Science (IMS), the Biobank Japan project will also investigate the pharmacogenetics of common diseases.

Samples and patient data for the project will be collected by a network of collaborating organizations and by several large private medical schools, including Nihon University, Juntendo University and the Tokushukai group. Genotyping will be undertaken by the SNP Research Center at the Institute for Physical and Chemical Research in Yokohama.

Critics say the project was launched without sufficient debate on its scientific value. The fact that none of the large public universities — with the exception of the IMS - is participating in the project has also raised eyebrows, but Nakamura argues that public university hospi- tals are ill-equipped to collect large numbers of samples. Private hospitals are also moving much more aggressively toward the standardization of therapeutic approaches, he says.

Although research on disease-related singlenucleotide polymorphisms has been well supported through the government's 'Millennium Project' (Nat. Med. 5, 1095; 1999), access to human specimens remains a major issue for Japanese researchers. As part of the new venture, a facility to store the collected specimens will be built at the IMS. For security reasons, however, medical and genetic data will be stored elsewhere, and will only be available to researchers in statistical form.

In retrospect, says Nakamura, the issue of sample collection should have been addressed early on in the Millennium Project. But a lack of coordination among ministries at the time would have made an endeavor like Biobank Japan impossible, he says.

Once the project is complete, scientists in academia and public-sector research institutes will have access to the samples. But the Japanese education ministry, which is financing the project, has yet to decide whether private companies will be granted access. In its present form, say industry insiders, the project does not sufficiently address industry's interests.

According to Shohei Yonemoto, a science policy analyst and director of the Center for Life Science and Society, a private think-tank near Tokyo, many of the legal and ethical issues surrounding the project have yet to be resolved. For example, Japan lacks legislation to protect patients in clinical studies, and there are no clear rules on the use of human materials for research. A new bill to protect personal information, the first of its kind in Japan, also explicitly exempts data used in scientific research.

Officials at Japan's Ministry of International Trade and Industry have now set up an expert group to help the ministry draft legislation for data protection in scientific research, but it is unclear when the new rules will be available.

Robert Triendl, Tokyo 